\title{
Ultrasound Assessment of Diaphragmatic Motion in Subjects With ARDS During Transpulmonary Pressure-Guided PEEP Titration
}

\author{
Roy J Cho, Alex Adams, Sum Ambur, Scott Lunos, Robert Shapiro, and Matthew E Prekker
}

\begin{abstract}
BACKGROUND: We aimed to investigate the effects of incremental PEEP titration in patients with ARDS on regional diaphragmatic motion with bedside ultrasound. METHODS: Dorsal diaphragmatic excursion (DDE) and ventral diaphragmatic excursion (VDE) were measured using anatomic M-mode ultrasonography of the right hemidiaphragm as PEEP was randomized to $-6,-3,+3$, and $+6 \mathrm{~cm} \mathrm{H}_{2} \mathrm{O}$ from baseline to achieve a positive transpulmonary pressure. Inter-operator variability of DDE was assessed in 10 separate subjects. RESULTS: A total of 14 subjects ventilated for ARDS were enrolled. Subjects had a mean age of $54 \pm 12 \mathrm{y}$, mean $\mathrm{P}_{\mathrm{aO}} / \mathrm{F}_{\mathrm{IO}_{2}}=137 \pm 54 \mathrm{~mm} \mathrm{Hg}$, and mean sequential organ failure assessment $(\mathrm{SOFA})$ score $=14 \pm 1$ ). Transpulmonary pressure, DDE, and DDE/VDE ratio increased with incremental PEEP titration $\left(-1.15 \mathrm{~cm} \mathrm{H}_{2} \mathrm{O}\right.$ vs $3.63 \mathrm{~cm} \mathrm{H}_{2} \mathrm{O}$, $P<.001 ; 4.9 \mathrm{~mm}$ vs $8.2 \mathrm{~mm}, P<.001$; and $62 \%$ vs $93 \%, P<.001$, respectively). When transpulmonary pressure became positive, a visual increase in DDE and DDE/VDE ratio 0.60 to 0.93 was observed (from $0.48 \mathrm{~cm}$ to $0.82 \mathrm{~cm}, \mathrm{R}^{2}=0.87, P=.02$; and $\mathrm{R}^{2}=0.93, P=.006$, respectively). There was high agreement in DDE measurements between 2 ultrasonographers (intra-class correlation $0.987, P<.001)$. CONCLUSIONS: DDE was affected by incremental PEEP titration toward a positive transpulmonary pressure. The ultrasound assessment using anatomic M-mode allowed for specific measurement of regional diaphragmatic excursion. This pattern of motion in the dependent regions of the diaphragm during PEEP titration in subjects with ARDS achieving a positive transpulmonary pressure may reflect a potential target for future studies in the bedside assessment for lung recruitment. (Clinical Trials.gov registration NCT02463773.) Key words: ARDS; PEEP; critical care ultrasound. [Respir Care 2020;65(3):314-319. (C) 2020 Daedalus Enterprises]
\end{abstract}

\section{Introduction}

The classic study by Froese and Bryan ${ }^{1}$ demonstrated that diaphragm motion is not uniform; rather, it displays

\footnotetext{
Dr Cho is affiliated with the Department of Pulmonary and Critical Care, University of Minnesota, Minneapolis. Mr Lunos is affiliated with the Clinical and Translational Science Institute, University of Minnesota, Minneapolis. Mr Adams and Drs Ambur, Shapiro, and Prekker are affiliated with the Hennepin County Medical Center, Pulmonary and Critical Care, Minneapolis, Minnesota.
}

The authors have disclosed no conflicts of interest.

Correspondence: Roy J Cho MD MHA, Department Pulmonary, Allergy, Critical Care and Sleep Medicine Earl E Bakken Medical Devices Center, University of Minnesota, M-Health 401 East River Parkway Suite 350 MMC 276; Room VCRC 146 Minneapolis, MN 55455. E-mail: choxx548@umn.edu.

DOI: $10.4187 /$ respcare.06643 regional variation in displacement that is dependent on spontaneous versus passive ventilation, the amount of tidal volume, and supine versus prone positioning. Specifically, there is less diaphragm displacement in the dependent region during passive, low tidal volume ventilation and a uniform piston-like displacement of the diaphragm at larger tidal volumes. This pattern of diaphragm movement may reflect areas of regional tidal volume distribution when dependent lung zones are atelectatic during passive small tidal volume ventilation and open during larger spontaneous tidal volume ventilation. The normal motion and position of the diaphragm during positive-pressure ventilation has been described in healthy volunteers, patients with COPD, and those who are critically ill undergoing a spontaneous breathing trial; however, there is no study investigating diaphragm motion in patients mechanically ventilated for ARDS.

Patients with ARDS have a pattern of heterogeneous lung injury resulting in high pleural pressure in the depen- 
dent lung regions, which are prone to atelectasis when end-expiratory alveolar pressure is inadequate. ${ }^{2,3}$ Such abnormalities could theoretically lead to altered diaphragmatic motion. Specifically, the effects of smaller tidal volume ventilation and the weight of the injured lung may diminish the passive movement of the dorsal diaphragm relative to its anterior counterparts during neuromuscular blockade. If this is correct, this association could be a potential target for bedside assessment for lung recruitment. Therefore, the purpose of this study was to evaluate the motion of the diaphragm in supine ventilated patients during neuromuscular blockade for ARDS and its relationship to incremental PEEP titration and when transpulmonary pressure becomes positive. We used bedside ultrasound with anatomic M-mode to obtain a detailed measurement of the dorsal diaphragm excursion (DDE) and ventral diaphragm excursion (VDE) during the study.

\section{Methods}

This was a prospective single-center cross-sectional study conducted in the medical ICU at Hennepin County Medical Center, an urban, tertiary-care hospital in Minneapolis, Minnesota. Written informed consent was obtained from surrogate decision makers prior to study enrollment. The human subjects research committee of the local institutional review board approved the study protocol.

Eligible patients were $\geq 18$ y old with a diagnosis of ARDS according to the Berlin definition. ${ }^{4}$ All subjects were ventilated with Puritan Bennett 840 ventilators (Covidien, Mansfield, Massachusetts) via volume-controlled continuous mandatory ventilation. All subjects were sedated and paralyzed. Exclusion criteria were any contraindication for nasogastric tube placement, pneumothorax or bronchopleural fistula, solid organ transplant recipient, known diaphragmatic paralysis, non-conventional mechanical ventilation strategy including prone positioning or extracorporeal membrane oxygenation, or hemodynamic instability defined as mean arterial pressure $<65 \mathrm{~mm} \mathrm{Hg}$ despite vasopressor support. At our institution, we titrate PEEP to keep static plateau pressures relatively high but not to exceed $28-30 \mathrm{~cm} \mathrm{H}_{2} \mathrm{O}$ as described by Mercat et al. ${ }^{5}$ Additionally, use of inhaled epoprostenol is largely at the discretion of the clinician; in general, inhaled epoprostenol is routinely used at the study institution to maintain $\mathrm{S}_{\mathrm{PO}_{2}}>90 \%$ and $\mathrm{F}_{\mathrm{IO}_{2}}<80 \%$ after PEEP titration.

The technique we used for ultrasound of the diaphragm was developed based on previous literature of basic diaphragm ultrasound and anatomic M-mode sonography. ${ }^{6-13}$ We used a 7.5-MHz phased-array probe (Vivid i, General Electric, Fairfield, Connecticut) loaded with anatomic Mmode software. Subjects were laid supine with elevation of the right arm to obtain an optimal area for image acquisi-

\section{QUICK LOOK}

\section{Current knowledge}

Current knowledge of diaphragmatic motion states that there is regional variation in displacement depending on active respiratory muscle use, tidal volume, and body position. Diaphragmatic excursion in patients with ARDS undergoing mechanical ventilation has not been previously evaluated.

\section{What this paper contributes to our knowledge}

In this study, we observed regional variation in diaphragmatic movement during passive ventilation of subjects with ARDS. We demonstrated that dorsal diaphragmatic excursion (DDE) improved when PEEP titration results in a positive transpulmonary pressure. These results may implicate DDE as a potential target or surrogate for lung recruitment.

tion. The right diaphragm was selected due to its higher fidelity in echogenicity with excursion similar to that of the left diaphragm. We used the mid-axillary line of the right hemidiaphragm for all measurements due to the optimal acoustic window offered by the liver. To obtain the best image for measurement, the M-mode horizontal sweep was set to low while reducing the gain until an optimal waveform was observed for analysis. Once an optimal image was captured, the first exploration line was placed perpendicular to the image, then the second exploration line was used to measure DDE, and a more ventral diaphragmatic excursion (VDE) located at the apex. DDE was measured as the exploration line dissected half-way between the middle and posterior diaphragm. VDE was measured as the exploration line dissected the apex of the diaphragm (Fig. 1).

Esophageal manometry was obtained using an esophageal balloon (CareFusion, Plymouth, Minnesota) inflated with $1 \mathrm{~mL}$ of air and recorded using a standard bedside transducer. The esophageal balloon was positioned in the distal third of the esophagus by identifying cardiac oscillations in the pressure waveform. Esophageal pressure tracings were recorded during an end-inspiratory and endexpiratory hold to obtain static estimates. Transpulmonary pressure was calculated as the difference between the alveolar and esophageal pressures.

We randomized applied PEEP between $-6,-3,+3$, and $+6 \mathrm{~cm} \mathrm{H}_{2} \mathrm{O}$ from the baseline PEEP prescribed by the treating clinician. Prior to each PEEP change, we performed a recruitment maneuver by ventilating for 2 min at $6 \mathrm{~cm} \mathrm{H}_{2} \mathrm{O}$ above the baseline PEEP to standardize each subject's lung volume history. ${ }^{14}$ In sequential order, we recorded ultrasound images of the right 


\section{PEEP and Diaphragm Motion in Subjects With ARDS}
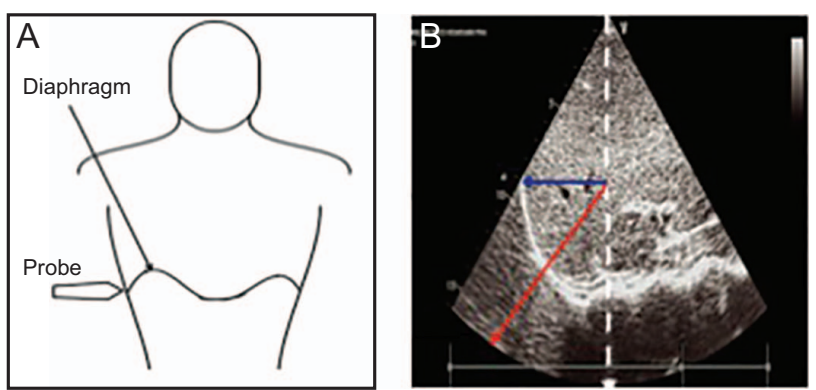

Fig. 1. Technique for measuring diaphragm excursion. A 7.5-MHz phased-array probe with anatomical M-mode capability was used for all measurements. A: The probe was positioned in the midaxillary line perpendicular to the posterior part of the diaphragm. $\mathrm{B}$ : Target ultrasound window to measure dorsal and ventral excursion. The initial exploration line (dotted line) was placed perpendicular to the image. For dorsal excursion, the second exploration line was angled to intersect halfway between the apex and the costodiaphragmatic recess (red arrow). For ventral excursion, the second exploration line was angled toward the apex of the diaphragm (blue arrow).

diaphragm excursion (ventral and dorsal region), followed by esophageal pressure at each PEEP level. We terminated the protocol in any subject who had a resting peak airway pressure $>60 \mathrm{~cm} \mathrm{H}_{2} \mathrm{O}, \mathrm{S}_{\mathrm{pO}_{2}}<85 \%$, mean arterial pressure $<60 \mathrm{~mm} \mathrm{Hg}$, or a cardiac dysrhythmia during the study.

Descriptive statistics (mean \pm SD for continuous variables; counts and proportions for categorical variables) were used to summarize subject characteristics and study measurements. Mixed effect models with a random intercept and slope for each subject were used to assess the association between PEEP levels and the study measures (outcomes). Inter-rater reliability was evaluated in 10 separate patients by 2 ultrasonographers using the intra-class correlation coefficient derived from a 2-way random effects model. ${ }^{15} P$ values of $<.05$ were considered statistically significant. All analyses were carried out using SAS 9.3 (SAS Institute, Cary, North Carolina).

\section{Results}

A total of 25 patients with ARDS were evaluated for enrollment during the 6-month study period, and 11 were excluded. Reasons for exclusion were absence of surrogate decision maker to give consent $(n=5)$, non-conventional mechanical ventilation strategy $(n=5)$, or de-escalation of care $(n=1)$. Therefore, 14 subjects with ARDS were enrolled in the study, having a mean age of $54 \pm 12 \mathrm{y}$, mean $\mathrm{P}_{\mathrm{aO}_{2}} / \mathrm{F}_{\mathrm{IO}_{2}}=137 \pm 54 \mathrm{~mm} \mathrm{Hg}$, and mean sequential organ failure assessment (SOFA) score of $14 \pm 1$. Ultrasound measurements were obtained in all subjects. There were no complications during esophageal balloon placement. Clinical and physiological characteristics of study subjects are summarized in Table 1.
Table 1. Demographic and Clinical Features

\begin{tabular}{|c|c|}
\hline Male & $5(35)$ \\
\hline Age, y & $54 \pm 12$ \\
\hline \multicolumn{2}{|l|}{ ICU diagnosis } \\
\hline Pneumonia & $11(80)$ \\
\hline Extrapulmonary sepsis & $1(10)$ \\
\hline Diffuse alveolar hemorrhage & $1(10)$ \\
\hline SOFA score & $14 \pm 1$ \\
\hline Total ventilator days & $5.5 \pm 3.4$ \\
\hline Net fluid on enrollment, $\mathrm{mL}$ & $-610 \pm 1,250$ \\
\hline Body mass index, $\mathrm{kg} / \mathrm{m}^{2}$ & $37 \pm 3.2$ \\
\hline \multicolumn{2}{|l|}{ Ventilator data } \\
\hline $\mathrm{P}_{\mathrm{aO}_{2}} / \mathrm{F}_{\mathrm{IO}_{2}}, \mathrm{~mm} \mathrm{Hg}$ & $137 \pm 54$ \\
\hline $\mathrm{F}_{\mathrm{IO}_{2}}, \%$ & $70 \pm 1$ \\
\hline Total PEEP, $\mathrm{cm} \mathrm{H}_{2} \mathrm{O}$ & $14.7 \pm 1$ \\
\hline Inhaled epoprostenol use & $14(100)$ \\
\hline Paralytic use & $14(100)$ \\
\hline \multicolumn{2}{|l|}{ Baseline lung mechanics } \\
\hline Peak pressure, $\mathrm{cm} \mathrm{H}_{2} \mathrm{O}$ & $36 \pm 2$ \\
\hline Plateau pressure, $\mathrm{cm} \mathrm{H}_{2} \mathrm{O}$ & $29.6 \pm 2.2$ \\
\hline Driving pressure, $\mathrm{cm} \mathrm{H}_{2} \mathrm{O}$ & $16 \pm 5$ \\
\hline $\mathrm{V}_{\mathrm{T}} / \mathrm{PBW}, \mathrm{mL} / \mathrm{Kg}$ & $6 \pm 0.1$ \\
\hline Respiratory system compliance, $\mathrm{mL} / \mathrm{cm} \mathrm{H}_{2} \mathrm{O}$ & $28.5 \pm 3$ \\
\hline Chest wall compliance, $\mathrm{mL} / \mathrm{cm} \mathrm{H}_{2} \mathrm{O}$ & $176.3 \pm 38.3$ \\
\hline Lung compliance, $\mathrm{mL} / \mathrm{cm} \mathrm{H}_{2} \mathrm{O}$ & $38.4 \pm 4.1$ \\
\hline \multicolumn{2}{|l|}{ Baseline diaphragmatic ultrasound } \\
\hline Ventral excursion, $\mathrm{mm}$ & $8.7 \pm 0.1$ \\
\hline Dorsal excursion, mm & $4.9 \pm 0.1$ \\
\hline Dorsal/ventral ratio & $0.62 \pm 0.1$ \\
\hline \multicolumn{2}{|l|}{$\begin{array}{l}\text { Data are presented as } n(\%) \text { or mean } \pm \text { SD. } N=14 \text { subjects. } \\
\text { SOFA }=\text { sequential organ failure score } \\
\text { PBW }=\text { predicted body weight } \\
\mathrm{V}_{\mathrm{T}}=\text { tidal volume }\end{array}$} \\
\hline
\end{tabular}

All subjects received a tidal volume of $6 \mathrm{~mL} / \mathrm{kg}$ predicted body weight (mean driving pressure $=16 \pm$ $5 \mathrm{~cm} \mathrm{H}_{2} \mathrm{O}$ ). Chest wall compliance was a negligible factor to the total decrease in respiratory system compliance (see Table 1). Baseline DDE, VDE, and DDE/VDE (ie, DE ratio) were $4.9 \pm 0.1 \mathrm{~mm}, 8.7 \pm 0.1 \mathrm{~mm}$, and $0.62 \pm 0.01 \%$, respectively. There was high agreement with DDE measurements between 2 ultrasonographers (intraclass correlation $0.987,95 \%$ CI $0.95-0.99, P<.001$ ).

A mixed effect model for each subject was analyzed to evaluate the association between PEEP titration and dependent variables, namely transpulmonary pressure, DDE, VDE and DE ratio (Fig. 2 and 3). The baseline transpulmonary pressure, DDE, and DE ratio significantly increased with incremental PEEP titration $(-1.15$ vs $3.63 \mathrm{~cm} \mathrm{H}_{2} \mathrm{O}, P<.001 ; 4.9$ vs $8.2 \mathrm{~mm}, P<.001$; $62 \%$ vs $93 \%, P<.001$; respectively), while VDE remained relatively unchanged despite increasing PEEP ( 8.7 vs $9.0 \mathrm{~mm}, P=.07$ ). One subject had a decrease in DDE and increase in VDE with PEEP escalation $(0.98 \mathrm{~cm}$ to $0.67 \mathrm{~cm}$ and 1.15 to $1.53 \mathrm{~cm}$; respectively). 

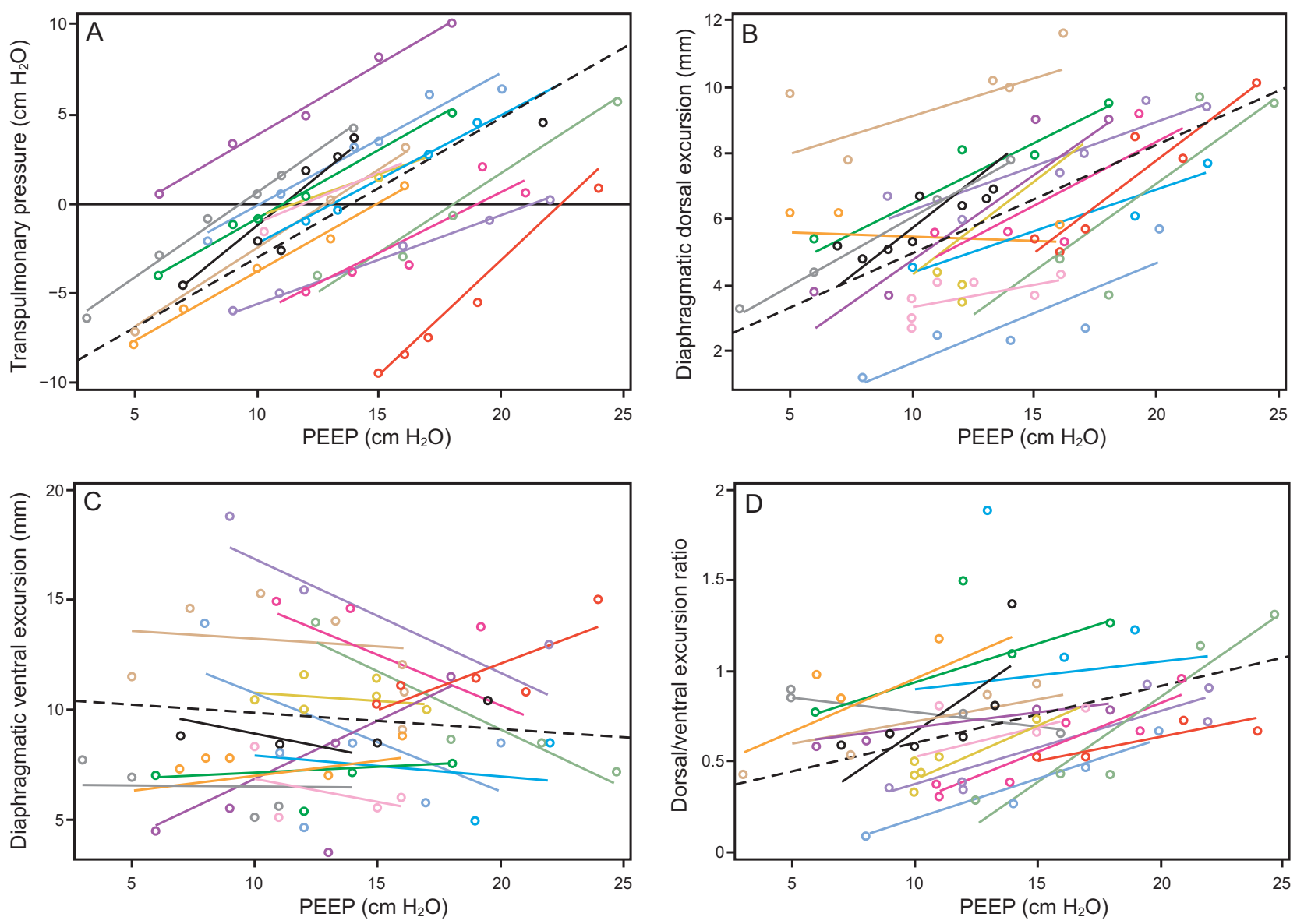

Fig. 2. A mixed effect model for each subject was used to estimate the association between PEEP and A: transpulmonary pressure $(\mathrm{b}=0.78,95 \% \mathrm{Cl} 0.67-0.90, P<.001)$, B: dorsal diaphragm excursion ( $\mathrm{b}=0.33,95 \% \mathrm{Cl} 0.24-0.43, P<.001)$, C: ventral diaphragm excursion $(\mathrm{b}=-0.07,95 \% \mathrm{Cl}-0.28-0.13, P=.45)$, and $\mathrm{D}$ : diaphragm excursion ratio $(\mathrm{b}=0.03,95 \% \mathrm{Cl} 0.02-0.05, P<.001)$.
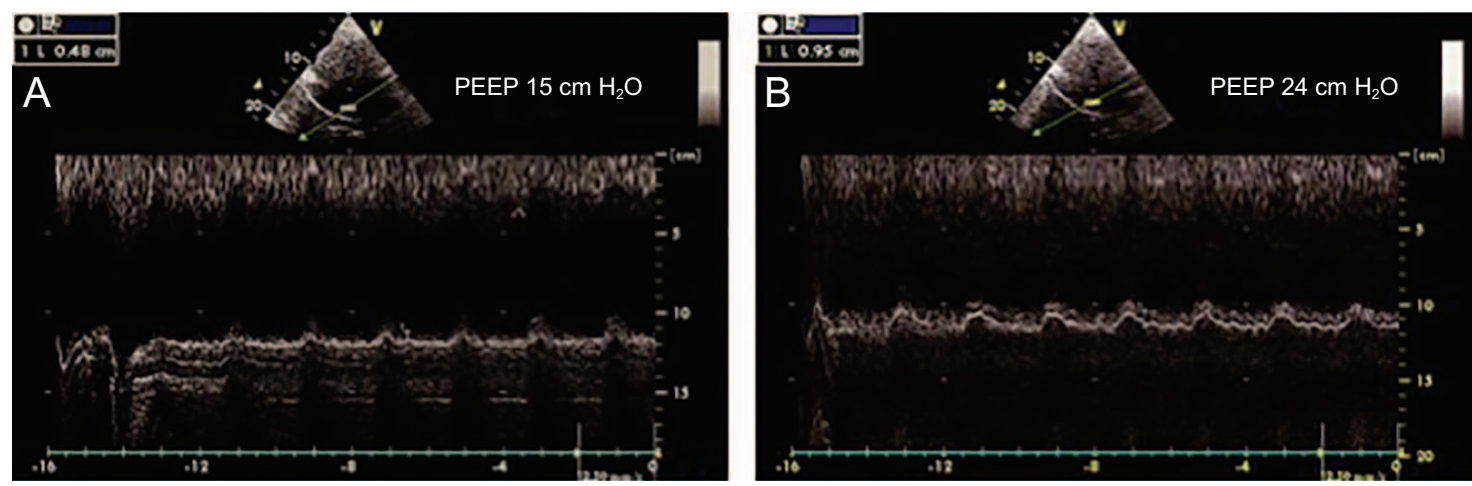

Fig. 3. Two-dimensional anatomic M-mode image and measurement of dorsal diaphragm excursion with applied $P E E P$ of $A$ : $15 \mathrm{~cm} \mathrm{H}_{2} \mathrm{O}$ and $\mathrm{B}: 24 \mathrm{~cm} \mathrm{H} \mathrm{H}_{2} \mathrm{O}$. There was an increase in dorsal diaphragm excursion from $0.48 \mathrm{~cm}$ to $0.95 \mathrm{~cm}$ between $\mathrm{A}$ and $\mathrm{B}$, respectively. This corresponded with an improvement in transpulmonary pressure from $-2.9 \mathrm{~cm} \mathrm{H}_{2} \mathrm{O}$ to $5.7 \mathrm{~cm} \mathrm{H}_{2} \mathrm{O}$, respectively.

The baseline PEEP at study enrollment was $14.7 \pm 1$ $\mathrm{cm} \mathrm{H}_{2} \mathrm{O}$. PEEP titration of +3 to $+6 \mathrm{~cm} \mathrm{H}_{2} \mathrm{O}$ above baseline (Figs. 3 and 4) corresponded with a transition to a positive transpulmonary pressure $\left(-1.15 \mathrm{~cm} \mathrm{H}_{2} \mathrm{O}\right.$ vs $\left.3.63 \mathrm{~cm} \mathrm{H}_{2} \mathrm{O}, 95 \% \mathrm{CI} 0.67-0.9, P<.001\right)$. At this tran- sition, there was an increase in dorsal diaphragm movement from $4.9 \mathrm{~mm}$ to $8.2 \mathrm{~mm}\left(\mathrm{R}^{2}=0.87, P=.02\right)$ and in DE ratio from 0.62 to $0.93\left(\mathrm{R}^{2}=0.93, P=.006\right)$. The ventral diaphragm did not show any appreciable correlation with transpulmonary pressure $\left(\mathrm{R}^{2}=0.07, P=.67\right)$. 


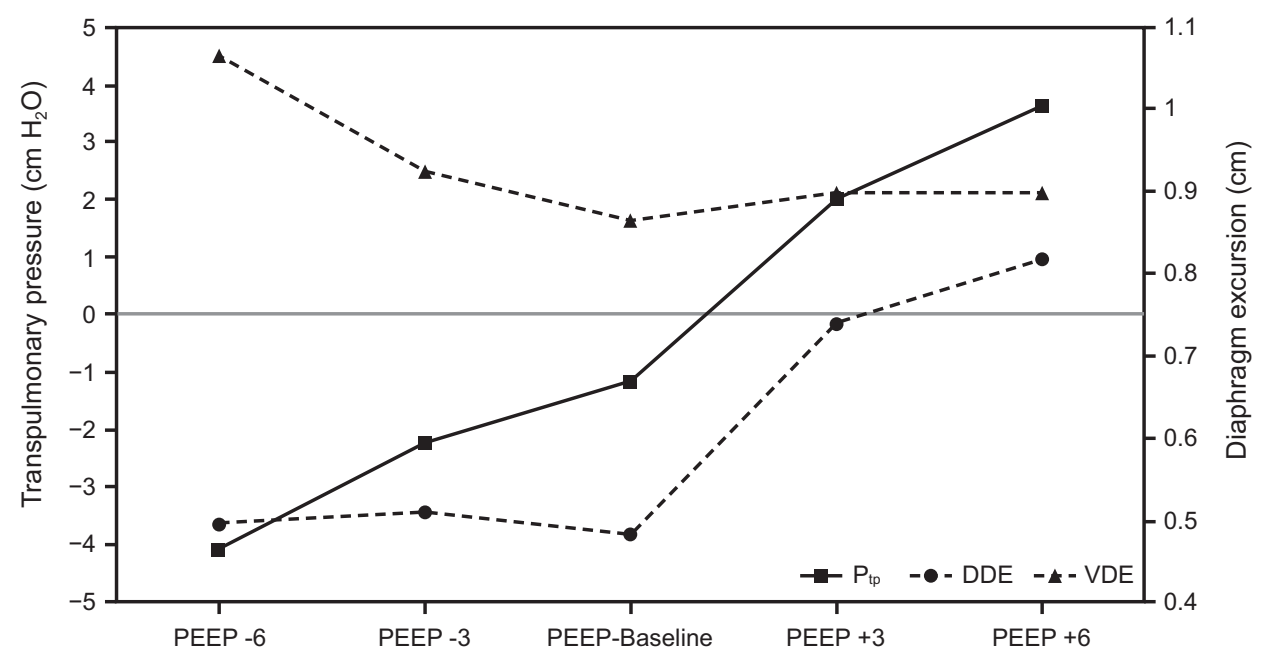

Fig. 4. Mean transpulmonary pressure, dorsal diaphragm excursion, and ventral diaphragm excursion in 14 subjects with ARDS plotted against PEEP stages. Increasing PEEP in subjects with fixed tidal volume resulted in a corresponding increase in transpulmonary pressure and DDE, with no change in VDE. $P_{\text {tp }}=$ transpulmonary pressure; DDE = dorsal diaphragm excursion; VDE = ventral diaphragm excursion.

\section{Discussion}

The mechanism comprising regional diaphragmatic motion is multifaceted, yet it is ultimately affected by horizontal and vertical pressure gradients (ie, abdominal and mediastinal/lung pressure, respectively), active respiratory muscle contraction and compliance of the chest wall. In healthy, supine, spontaneously ventilated subjects, the vertical pressure gradient and chest wall compliance are normal; therefore, the diaphragmatic motion is dependent largely on the hydrostatic abdominal pressure gradient. ${ }^{1,16}$ In these subjects, the shape of the human diaphragm (ie, the curved, stretched dorsal diaphragm along with its crural and costal muscle segments) allow for contraction that overcomes the horizontal hydrostatic pressures in the abdomen. Thus, the dorsal diaphragm exhibits greater excursion than its anterior counterparts. During administration of neuromuscular blockade, regional excursion is determined by two opposing forces: a uniform force applied to the airway during mechanical ventilation and the non-uniform horizontal hydrostatic pressure gradient assumed by the abdominal contents. In patients with ARDS, the weight of the injured lung and mediastinal components result in a higher vertical pressure gradient as compared to healthy patients, which may amplify the effect on regional diaphragmatic motion. Specifically, the smallest diaphragmatic excursion would occur where the transdiaphragmatic pressure gradient is at its lowest, particularly at the dependent regions of the diaphragm. However, uniform force applied during mechanical ventilation may overcome these pressure gradients; theoretically then, we may observe an improvement in excursion of the dependent region of the diaphragm.

In patients with ARDS, the pleural pressure surrounding the lung is elevated due to the hydrostatic pressure exerted by the injured lung, mediastinum, and abdominal contents. ${ }^{5,16-20}$ Previous studies in patients with ARDS reported that pleural pressure is greatest in the dependent lung regions, which are prone to atelectasis when endexpiratory alveolar pressure (ie, PEEP) is inadequate. One emerging strategy to determine PEEP insufficiency is to measure end-expiratory transpulmonary pressure, which, when positive, is suggestive of an alveolar pressure that exceeds pleural pressure and results in alveolar patency in the dependent lung regions. ${ }^{6,7}$ For that reason, close examination of dorsal diaphragm motion in patients with ARDS when transpulmonary pressure becomes positive may represent a unique opportunity to estimate the recruiting effects of PEEP and provide a direct bedside assessment with ultrasound (Figs. 3 and 4).

In this study, we observed regional variation in excursion between the dorsal and ventral diaphragm during passive tidal ventilation $(4.9 \pm 0.1 \mathrm{~mm}$ vs $8.7 \pm 0.1 \mathrm{~mm}$; respectively). After transpulmonary pressure-guided lung recruitment, we observed a measurable improvement in the dorsal diaphragm excursion $(4.9 \mathrm{~mm}$ to $8.2 \mathrm{~mm}$, $\left.\mathrm{R}^{2}=0.87, P=.02\right)$. Comparatively, the work by Froese and Bryan ${ }^{1}$ reinforces this concept, whereby the increased vertical pressure gradient in subjects with ARDS contribute to smaller excursion in the dependent diaphragm, which can be shown to improve with PEEP. This phenomenon illustrates the direct effect of PEEP in providing a more uniform distribution of ventilator-driven gas, in particular toward the dependent regions of the lung as illustrated by a positive transpulmonary pressure. Previously, diaphragmatic motion has largely been studied in healthy volunteers, COPD, and subjects undergoing spontaneous breathing trials; however, to our knowledge this is the first study 


\section{PEEP and Diaphragm Motion in Subjects With ARDS}

to describe regional diaphragmatic motion in subjects mechanically ventilated for ARDS.

Thoracic ultrasound by intensivists is increasingly becoming a valuable diagnostic tool in the assessment of critically ill patients. ${ }^{6}$ Previous imaging modalities in assessing diaphragmatic motion are limited by a lack of portability and direct quantitative movement, as well as by risk from ionizing radiation. M-mode ultrasonography allows continuous recording of motion in real time, and therefore is an ideal technique to assess the amplitude, duration, and velocity of diaphragm displacement at the bedside. In addition, we recommend using the anatomic M-mode to measure regional diaphragm movement because it allows for a precise secondary exploration line to cut the diaphragm at the dorsal location. This software is not standard in most ultrasound machines, but, to our knowledge, it can be equipped in most ventilator models made by other manufacturers. As observed in this study, bedside ultrasound can be easily coupled with other techniques, such as airway pressure measurements, for comparative physiological studies. Overall, bedside sonography proved to be a simple, well tolerated, and reproducible method of assessing hemidiaphragmatic movement between the 2 ultrasonographers in this study.

This study has several limitations. Our findings are based on a single-center experience with skilled physician-ultrasonographers and describes a novel technique and observations that necessitate prospective validation prior to clinical application. Our ultrasound measurements were performed during dynamic conditions, whereas transpulmonary pressure measurements were made during static conditions; this is a potential source of bias. To minimize these confounders, we randomized PEEP and blinded the ultrasonographers to the esophageal pressure and therefore the transpulmonary pressure. Despite these limitations, we feel that our findings are noteworthy in providing a novel technique with a potential application to guide PEEP therapy in ARDS.

\section{Conclusions}

The results of this exploratory study suggest that regional variation in diaphragmatic movement occurs in patients ventilated for ARDS during neuromuscular blockade. Additionally, we report a direct relationship between dorsal diaphragm movement and transpulmonary pressureguided lung recruitment. We have provided a detailed description for the bedside use of ultrasound to measure regional differences in diaphragm excursion using anatomic M-mode. Distinctively, this is the first study to assess the diaphragm motion in subjects with ARDS using bedside ultrasonography. The implications of our findings for future research is the application of this concept to guide PEEP therapy in patients with ARDS.

\section{REFERENCES}

1. Froese A, Bryan C. Effects of anesthesia and paralysis on diaphragmatic mechanics in man. Anesthesiology 1974;41(3):242-254.

2. Talmor DS, Fessler HE. Are esophageal pressure measurements important in clinical decision-making in mechanically ventilated patients? Respir Care 2010;55:162-172.

3. Talmor D, Sarge T, Malhotra A, O'Donnell CR, Ritz R, Lisbon A, et al. Mechanical ventilation guided by esophageal pressure in acute lung injury. N Engl J Med 2008;359(20):2095-2104.

4. ARDS Definition Task Force. Acute respiratory distress syndrome: the Berlin definition. JAMA 2012;307(23):2526-33.

5. Mercat A, Richard JCM, Vielle B, Jaber S, Osman D, Diehl JL, et al. Positive end-expiratory pressure setting in adults with acute lung injury and acute respiratory distress syndrome. JAMA 2008;299(6):646-655.

6. Lichtenstein D. Lung ultrasound in the critically ill. Ann Intensive Care 2014;4(1):1-12.

7. Boussuges A, Gole Y, Blanc P. Diaphragmatic motion studies by M-mode ultrasonography. Chest 2009;135(2):391-400.

8. Cohen E, Mier A, Heywood K, Murphy K, Boultbee J, Guz A. Excursion-volume relation of the right hemidiaphragm measured by ultrasonography and respiratory airflow measurements. Thorax 1994; 1994:885-889.

9. Epelman M, Navarro OM, Daneman A, Miller SF. M-mode sonography of diaphragmatic motion: description of technique and experience in 278 pediatric patients. Pediatr Radiol 2005;35:661-667.

10. Ayoub J, Cohendy R, Dauzat M, Targhetta R, De la Coussaye JE, Bourgeois JM, et al. Non-invasive quantification of diaphragm kinetics using m-mode sonography. Can J Anaesth 1997;44:739-744.

11. Testa A, Soldati G, Giannuzzi R, Berardi S, Portale G, Gentiloni Silveri N. Ultrasound M-mode assessment of diaphragmatic kinetics by anterior transverse scanning in healthy subjects. Ultrasound Med Biol 2011;37:44-52.

12. Ueki J, De Bruin PF, Pride NB. In vivo assessment of diaphragm contraction by ultrasound in normal subjects. Thorax 1995;50:1157-1161.

13. Matamis D, Soilemezi E, Tsagourias E, Akoumianaki E, Dimassi S, Boroli F, et al. Sonographic evaluation of the diaphragm in critically ill patients. Technique and clinical applications. Intensive Care Med 2013;39(5):801-10.

14. Nishida T, Suchodolski K, Schettino GPP, Sedeek K, Takeuch M, Kacmarek RM. Peak volume history and peak pressure-volume curve pressures independently affect the shape of the pressure-volume curve of the respiratory system. Crit Care Med 2004;32(6):1359-1364.

15. Nickerson C. A concordance correlation coefficient to evaluate reproducibility. Biometrics 1997;53(4):1503-1507.

16. Krayer S, Rehder K, Vettermann J, Didier EP, Ritman EL. Position and motion of the human diaphragm during anesthesia-paralysis. Anesthiology 1989;70:891-898.

17. Suter PM, Fairley B, Isenberg MD. Optimum end-expiratory airway pressure in patients with acute pulmonary failure. N Engl J Med 1975;292(6):284-289.

18. Brower RG, Lanken PN, MacIntyre N, Matthay MA, Morris A, Ancukiewicz M, et al. Higher versus lower positive end-expiratory pressures in patients with acute respiratory distress syndrome. N Engl J Med 2004;351:327-336.

19. Meade MO, Cook DJ, Guyatt GH, Slutsky AS, Arabi YM, Cooper DJ, et al. Ventilation strategy using low tidal volumes, recruitment maneuvers, and high positive end-expiratory pressure for acute lung injury and acute respiratory distress syndrome: a randomized controlled trial. JAMA 2008;299:637-645.

20. Grasso S, Fanelli V, Cafarelli A, Anaclerio R, Amabile M, Ancona $\mathrm{G}$, Fiore T. Effects of high versus low positive end-expiratory pressures in acute respiratory distress syndrome. Am J Respir Crit Care Med 2005;171:1002-8. 